\title{
Preface
}

\section{Special issue: Selected contributions from the 12th European Conference on the Mathematics of Oil Recovery (ECMOR XII)}

\author{
Jan Dirk Jansen \\ Published online: 5 February 2012 \\ (C) The Author(s) 2012. This article is published with open access at Springerlink.com
}

The 12th European Conference on the Mathematics of Oil Recovery (ECMOR XII) was held at Keble College in Oxford (UK) from 6 to 9 September 2010. ECMOR has been a bi-annual event since 1988 focusing on the mathematical aspects of geo-modelling and reservoir simulation. Initially organized independently, ECMOR has been part of the regular conference program of the European Association of Geoscientists and Engineers (EAGE) since 1998. In Oxford, a total of 88 oral presentations and 35 posters covered a wide range of topics. The full list of papers presented at the conference can be found on the EAGE website [1], and all papers are electronically accessible via the EarthDoc online data base [2]. In this issue of Computational Geosciences a selection of papers is reproduced, most of them expanded, and all of them peer reviewed through the usual process. I like to thank the anonymous reviewers, the EAGE conference organisers Sandra Hermus and Marjolein Verweij, and my co-members of the ECMOR program committee:

Ivar Aavatsmark (University of Bergen)

Alberto Cominelli (Eni SpA)

Louis Durlofsky (Stanford University)

Christopher Farmer (chairman)

(Schlumberger and University of Oxford)

Dominique Guérillot (Terra 3E SAS)

Dayal Gunasekera (Schlumberger)
Andreas Harrer (Heinemann Oil GmbH)

Rainer Helmig (University of Stuttgart)

Stefano Mantica (ENI Exploration and Production)

Roland Masson (University of Nice Sophia Antipolis)

Gillian Pickup (Heriot-Watt University)

Jean-Jacques Royer (ENSG-CRPG)

Pierre Samier (Total)

Arne Skorstad (Roxar)

John Williams (BP)

Iskander Zakirov (Lukoil)

A special word of thanks goes to Christopher Farmer, who has been a passionate ECMOR committee member since the very beginning, initially affiliated to the Atomic Energy Agency, thereafter Schlumberger and most recently to the Oxford Centre for Collaborative Applied Mathematics (OCCAM) at Oxford University. Chris skilfully chaired the ECMOR XII meeting and arranged a high quality program in a very inspiring environment. After 12 conferences $(13$ in his own counting, starting from the 'pre-ECMOR' in Cambridge, 1987 [3, 4]), Chris decided to step down to redirect his research efforts to a broader range of topics. On behalf of the entire committee I like to thank him for his many contributions and wish him luck in his continued mathematical career.

Jan Dirk Jansen Special Issue Editor

Open Access This article is distributed under the terms of the Creative Commons Attribution License which permits any use, distribution, and reproduction in any medium, provided the original author(s) and the source are credited.
J. D. Jansen $(\varangle)$

Department of Geotechnology, Delft University

of Technology, Delft, South Holland, Netherlands

e-mail: J.D.Jansen@tudelft.nl 


\section{References}

1. http://www.eage.org

2. http://www.earthdoc.org

3. Edwards, S., King, P.R. (eds.): Mathematics in Oil Production; Based on the Proceedings of a Conference by the Institute of
Mathematics and its Applications on Mathematics in Oil Production, Held in Robinson College, Cambridge in July 1987. Clarendon (1988)

4. Farmer, C.L.: ECMOR success has stressed oilfield mathematics in oil recovery calculations. First Break 28(11). http://fb.eage.org/content.php?id=42758 (2010) 